Article

\title{
A Community Energy Transition Model for Urban Areas: The Energy Self-Reliant Village Program in Seoul, South Korea
}

\author{
Hana Kim \\ Corporate Course for Climate Change, Sejong University, Seoul 151742, Korea; hanakim0729@sejong.ac.kr; \\ Tel.: +82-2-3408-4353
}

Received: 12 June 2017; Accepted: 13 July 2017; Published: 18 July 2017

\begin{abstract}
While community energy initiatives are on the rise, community actions for energy transition in Asian countries have rarely been studied. While it is difficult for community energy initiatives to develop spontaneously in Seoul, there are some success stories there. This study places these successes in context. It analyzes municipal documents, including unpublished materials from municipal meetings, in order to examine how the Seoul Metropolitan Government (SMG) created enabling conditions for promoting community energy initiatives. This study also conducted interviews to explore unsolved issues related to the Energy Self-Reliant Village (ESV) program. The SMG encouraged collective action through financial, administrative, and informational support. Also, this study found that Seoul's ESV program fostered communities by raising the sense of locality and responsibility and community spirit through various educational programs. The ESV program supported the continuity of community by providing guidelines that relieved the burden on community members. The SMG played a significant role in promoting community engagement in energy transition by affecting internal and external conditions. This study provides meaningful insights that other municipalities, especially large urban areas, can follow to foster community actions for energy transition.
\end{abstract}

Keywords: community energy; community for energy transition; energy self-reliant villages; one less nuclear power plant policy; community-internal conditions; community-external conditions

\section{Introduction}

Community engagement in energy transition benefits not only the community itself but also those outside the community. First, community initiatives reflect local or micro-scale circumstances and priorities better than municipal policies would [1]. Second, community energy provides opportunities for capturing economic gains through energy saving and local economic regeneration [2,3]. Third, acting together as a community can give participants "an important sense of being something" [4] (p. 185) and, in turn, can enhance cohesion within the community [5]. Acting together within communities can contribute to the longevity of the engagement [6]. Through engagement in these activities, public awareness of climate change and energy issues can be enhanced [7]. In addition, community initiatives also complement central governments' efforts to achieve the Nationally Determined Contributions (NDCs) established under the Paris Agreement.

Due to these benefits, community actions for energy transition have been increasing. There are more than 2400 community-driven energy cooperatives in Europe [8]. These community energy initiatives are primarily located in Northern European countries [3]. There were 772 renewable energy cooperatives in Germany in 2014, 500 in Scotland in 2015, and 500 in the Netherlands in 2015 [9]. Since information about these decentralized activities is not systematically reported or collected [9], the actual number of energy communities is likely to be larger. Studies of community energy parallel the 
locations of this activity, focusing especially on Northern European countries. Only a few examples in Asia have been investigated [10].

Furthermore, in rural areas, communities are often identified with villages, and members of communities are relatively homogeneous with respect to their social and economic situation. In contrast, urban communities are more heterogeneous and diverse [11]. Furthermore, people in cities are less likely to live in proximity to extended families [12]. A sense of community depends on a "shared emotional connection", which can only be built over time [13]. In growing urban areas, this sense of community is unlikely to develop easily. Therefore, community energy initiatives are more difficult in urban areas.

Seoul demonstrates examples of successful urban community energy initiatives, called Energy Self-Reliant Villages (ESVs). The ESV model has spread domestically (e.g., to Siheung-si, South Korea), and has attracted the interest of citizens and researchers in other countries (e.g., Taiwan) [14]. The Seoul Metropolitan Government (SMG) has tried to build communities that have a shared vision about energy self-sufficiency. It has supported their collective actions through the ESV program, which has been in place since 2012. As of 2017, there are 75 ESVs practicing actions ranging from individual installation of solar panels to collective energy saving activities [15]. These ESVs are unique in that these community energy activities are being implemented in a city where pre-existing communities have been dismantled through the process of industrialization and urbanization, and new communities rarely have been created [16]. Therefore, the ESV program can be a model that other large cities could adopt to restore communities and mobilize collective action for energy transition.

Although several studies have explored ESVs in Seoul, the enabling conditions for their success remain unexplored. Park and Yun [17] explored how energy citizenship has been fostered through ESV activities. They conducted a case study of one ESV to investigate what factors influenced the development of energy citizenship. Cho and Yun [18] examined why individuals participated in ESV collective action from the perspective of ecological citizenship. The structural context that enables these community activities has not yet been investigated, however. Sperling [19] argued for understanding the context of community energy initiatives: "these contextual factors and their interrelations should be understood in detail, if we want to make sense of the specific reasons for why community energy projects succeed or fail, as well as for decision makers and local practitioners to be able to design adequate policies and processes that can promote the former and prevent the latter" (p. 885).

This study focuses on the SMG's contribution to the ESVs from the perspective of conditions internal and external to the community. The key questions are "How does the SMG promote ESVs by making internal and external conditions more favorable?" and "Which challenges remain unsolved regarding ESV activities?" Accordingly, this case study of ESVs can provide meaningful insights for other metropolitan cities as they try to mobilize community actions for energy transition or other sustainability goals. To answer the aforementioned questions, this study conducts a literature review, analyzes published and unpublished SMG documents, and carries out semi-structured interviews with officials of the Energy Citizen Cooperation Office (ECCO) at the Climate and Environment Headquarters of the SMG and with leaders of ESVs on site visits from 2015 to 2017. The author participated in internal meetings of the Energy Community/Welfare Division of the Implementation Council for One Less Nuclear Power Plant every month in 2017 to discuss relevant issues and collect data. The author also collected data by participating in the ESVs' interim and final reporting.

This article is organized as follows. The following section presents the analytical framework for examining the SMG's contribution to the ESVs. Section 3 summarizes the methodology. Section 4 briefly surveys the One Less Nuclear Power Plant and the Community Building Project, which are closely related to the ESV program. Section 5 explores the status and achievements of ESVs. Section 6 analyzes and discusses the SMG's contribution to creating the enabling conditions for ESV activities. Section 7 discusses challenges that remain unsolved even with the SMG's support. Section 8 provides some implications of the ESV model and the limitations of this study. 


\section{Communities for Energy Transition}

\subsection{Communities for Energy Transition}

Magnani and Osti [3] categorize three different uses of the term "community" in the community energy literature (Table 1). First, communities are a significant stakeholder in decisions about the introduction of energy facilities or initiatives. The South Korean government began community energy initiatives in rural areas in 2009. At that time, the role of communities was limited to discussions about the siting and location of renewable energy facilities (e.g., biomass plants) [20]. Second, communities can be conceptualized as spaces where sustainability actions, from individual PV installations to cooperative energy saving, are carried out "by the fact that they belong to the same territory" [3] (p. 148). Third, in communities, a group of people with shared visions or interests acts collectively and individually even though they may not live in the same vicinity [3].

Community may include one or more of the concepts listed in Table 1. The geographic and relational concepts of community are not mutually exclusive [21]. Also, although collective actions may begin by resisting the siting of noxious facilities, e.g., nuclear waste disposal facilities, communities can extend their activities to alternative energy, as seen in the case of Buan County, South Korea [22].

Table 1. Concepts of community in the community energy literature.

\begin{tabular}{cll}
\hline Concept & \multicolumn{1}{c}{ Description } & \multicolumn{1}{c}{ Example } \\
\hline Community as stakeholder & $\begin{array}{l}\text { Significant stakeholders in } \\
\text { decisions about the installation of } \\
\text { energy facilities or the } \\
\text { implementation of energy } \\
\text { initiatives within communities. }\end{array}$ & Social acceptance of wind farms. \\
\hline Community as space/place & $\begin{array}{l}\text { Space where collective action } \\
\text { happens due to geographic } \\
\text { proximity. }\end{array}$ & $\begin{array}{l}\text { Government-driven community } \\
\text { energy projects. }\end{array}$ \\
\hline Community of shared interest or \\
vision & $\begin{array}{l}\text { A group of people who share } \\
\text { interests and visions. }\end{array}$ & $\begin{array}{l}\text { Collective energy saving } \\
\text { campaigns beyond the community } \\
\text { boundaries; dispersed investors in } \\
\text { a cooperative project. }\end{array}$ \\
\hline
\end{tabular}

Source: The author built this table based on $[3,7,23]$.

Communities are more difficult to develop or sustain in urban areas than in rural areas. Nevertheless, because living in the same locality often lets people be confronted by common challenges and receive common benefits [12], this occasionally becomes the driver for collective actions in urban areas, e.g., opposition to the siting of unpleasant facilities in a neighborhood [24]. Therefore, even in urban areas where communities are less likely to develop spontaneously, there is a chance that people may cooperate if there are benefits from collective actions on energy initiatives, such as reducing the transaction costs and project risks [25].

Community actions for energy transition can be categorized according to various criteria: profit or non-profit distribution [26] or models of community ownership [27]. In urban areas, community energy projects are more likely to be implemented without close and direct interaction among members. Collective investment in renewable energy facilities through cooperatives is a representative example. In these activities, communities function according to shared visions or interests. The ESVs that will be explored in the following sections have both features, community as place and community of shared interest, at the same time.

\subsection{Internal and External Context Related to Communities for Energy Transition}

A great deal of literature has explored the factors affecting communities for energy transition and their activities. Some studies explore individual motivations for participating in community energy initiatives $[7,25,28]$. Others investigate the impacts of structural factors, e.g., policies, on the success of 
community energy activities $[1,3,29,30]$. Although it is important to examine the impacts of individual factors on community energy initiatives, community energy also needs to be explored from a more comprehensive context because its success is context-dependent. Recently, Sperling [19] took a more structured approach to exploring the internal and external contextual conditions that enabled success in Samsø, Denmark. Since communities are "embedded in and constituted by dynamics between socio-cultural, biophysical, economic, political, and legal subsystems", [31] (p. 5117) community initiatives can be promoted or discouraged by those conditions $[25,30]$. Therefore, exploration of community energy initiatives needs to account for these conditions. Sperling [19] refers to these conditions as the external context. At the same time, the success of community energy is also closely related to "the local context of the communities", which is the internal context. This study follows and modifies the internal and external conditions that Sperling [19] detailed and utilizes them as a framework for analyzing the SMG's contribution to the creation of enabling conditions.

Sperling [19] identified the following internal conditions related to community energy: local traditions and history of cooperative projects, community spirit, sense of locality and responsibility, entrepreneurial individuals, networks, and guiding visions and plans. Community spirit is closely related to community with shared vision or interests. People with common interests gather and act together. In addition, sense of locality and responsibility is closely related to the concept of community as place. Living in the same locality faces people with common challenges, which often lead them to act with responsibility [3,19]. Guiding visions suggest a clear direction for communities to follow [19]. Continuous community action depends on "safeguarding continuity, exercising effective team leadership, and attracting membership" [32] (p. 669). In other words, the development of an organization affects community energy projects.

External conditions incorporate "contextual and structural factors", including "the rules and procedures for project planning and implementation, available subsidies, and the attitude of market and government partners" [30] (p. 2). For example, if contextual and structural arrangements are not favorable, community actions for energy transition often face financial challenges. These challenges can be overcome with changes to economic, political, and legal systems [30]. Recognizing this, many national and local governments provide incentives to mobilize community energy activities [33]. Bulkeley and Kern [34] developed a typology of governing modes of local governments. While each mode of governing can affect community engagement in energy initiatives, the enabling mode of governing fosters citizens' engagement in energy initiatives by providing incentives and increasing public awareness through education. Guiding visions and plans impact communities internally as well as externally. The guiding visions and plans fall in to the mode of 'governing by authority', which is a typical form of governing mode of local government such as setting up regulations and directions [34]. The guiding visions can change the attitude of market and government partners by providing other stakeholders, such as investors, with the authority and credibility for community activities [19]. Expert assistance is also another factor affecting external conditions [19].

In addition to these non-technological conditions, because the "physical layout of our built environment" affects collective actions for energy transition [32], the external context for community energy can be more comprehensive. For example, if the current built environment is favorable to community actions (e.g., easier installation of renewable facilities), community energy might be promoted. Because the development of economically feasible technologies also affects community energy activities, the author included technological conditions in the analysis of community energy initiatives, while Sperling [19] overlooked this condition in the framework. This study will examine the role of the SMG using the important conditions that relate to community energy initiatives (see Table 2). 
Table 2. Community-external and community-internal conditions for community energy initiatives.

\begin{tabular}{|c|c|}
\hline Community-External conditions & Community-Internal Conditions \\
\hline $\begin{array}{l}\text { Technological condition } \\
\text { - Physical layout of the } \\
\text { built environment } \\
\text { - } \quad \text { Economic feasibility of technologies } \\
\text { Non-technological conditions } \\
\text { - The rules and procedures for project } \\
\text { planning and implementation } \\
\text { - } \quad \text { Tvailable subsidies } \\
\text { The attitude of market and } \\
\text { government partners } \\
\text { Expert assistance }\end{array}$ & $\begin{array}{l}\text { - } \quad \text { Local traditions and history of cooperative projects } \\
\text { - } \quad \text { Community spirit } \\
\text { - } \quad \text { Comse of locality and responsibility } \\
\text { - Entrepreneurial individuals } \\
\text { - Networks } \\
\text { - } \quad \text { Guiding visions and plans }\end{array}$ \\
\hline
\end{tabular}

Source: The author modified Table 1 of [19].

\section{Methodology}

To examine how the SMG affected the conditions internal and external to the communities that resulted in ESV success, this study used several sources of data, including a set of statistics and published and unpublished SMG documents. In addition, the author collected relevant data while participating as a member in monthly meetings of the Energy Community/Welfare Division of the Implementation Council for One Less Nuclear Power Plant. This division of this advisory council consists of about 10 people, including municipal officials, researchers, officials from related organizations, and representatives of civil society. This division operates as an advisory board to discuss issues related to the ESVs and recommends enhancements to the ESV program. The author also collected data by participating in the initial and final ESV reporting in 2016, during which each ESV gathered and presented its plans and achievements. Based on these collected data, this study analyzed the SMG's role in promoting the ESVs.

Complementing these data, semi-structured in-depth interviews were conducted to explore unsolved challenges facing the ESV program. Interviews with leaders of two major ESVs were carried out on 26 November 2015, and 12 April 2017. One interviewee manages a single-family home ESV (12 April 2017), and the other manages a leading multi-unit residential building ESV (26 November 2015). In addition, two municipal government officials at the SMG's Energy Citizen Cooperation Office were interviewed on 22 March 2017. That office is in charge of the overall implementation of the ESV program.

\section{Two Visions for One: One Less Nuclear Power Plant Policy and Community Building Project}

\subsection{One Less Nuclear Power Plant Policy (OLNPP)}

Situated in northwestern South Korea (See Figure 1), Seoul is a metropolitan city that houses about 10.2 million residents as of 2016. This city consumes a large amount of energy, most of which comes from distant regions in South Korea. As of 2011, Seoul's electricity consumption (41,824 GWh) accounted for $10.9 \%$ of the national total, while the city's power self-sufficiency was only $2.95 \%$. This means that Seoul is indebted to other power generating cities and is complicit in the environmental damage and social conflicts related to the power supply system in those regions. Seoul's power consumption increased by 12\% from 2006 (41,826 GWh) to 2011 (46,903 GWh) [35].

In 2012, the SMG initiated the OLNPP to respond to global warming and to relieve the environmental and social burdens on other regions caused by its energy consumption. This policy aimed to reduce energy consumption by 2 MTOE (Million Tonnes of Oil Equivalent) by 2014, which is equivalent to the amount of energy generated from one nuclear power plant. The SMG also pursued increasing its power self-sufficiency rate to $8 \%$ by 2014 . In the first phase of the OLNPP, 
the implementation plan consisted of 71 projects that fell into six policy agendas. The six agendas were as follows: (1) increase new and renewable energy installation, (2) enhance building energy efficiency, (3) establish an environmentally friendly and energy-efficient transportation system, (4) create energy-related jobs, (5) shift towards being a low-energy consuming city, and (6) build a citizen-driven low-energy consuming culture. Various projects, including the ESV program, have been implemented to reach these targets. Consequently, the SMG successfully met the target six months earlier than planned [35].

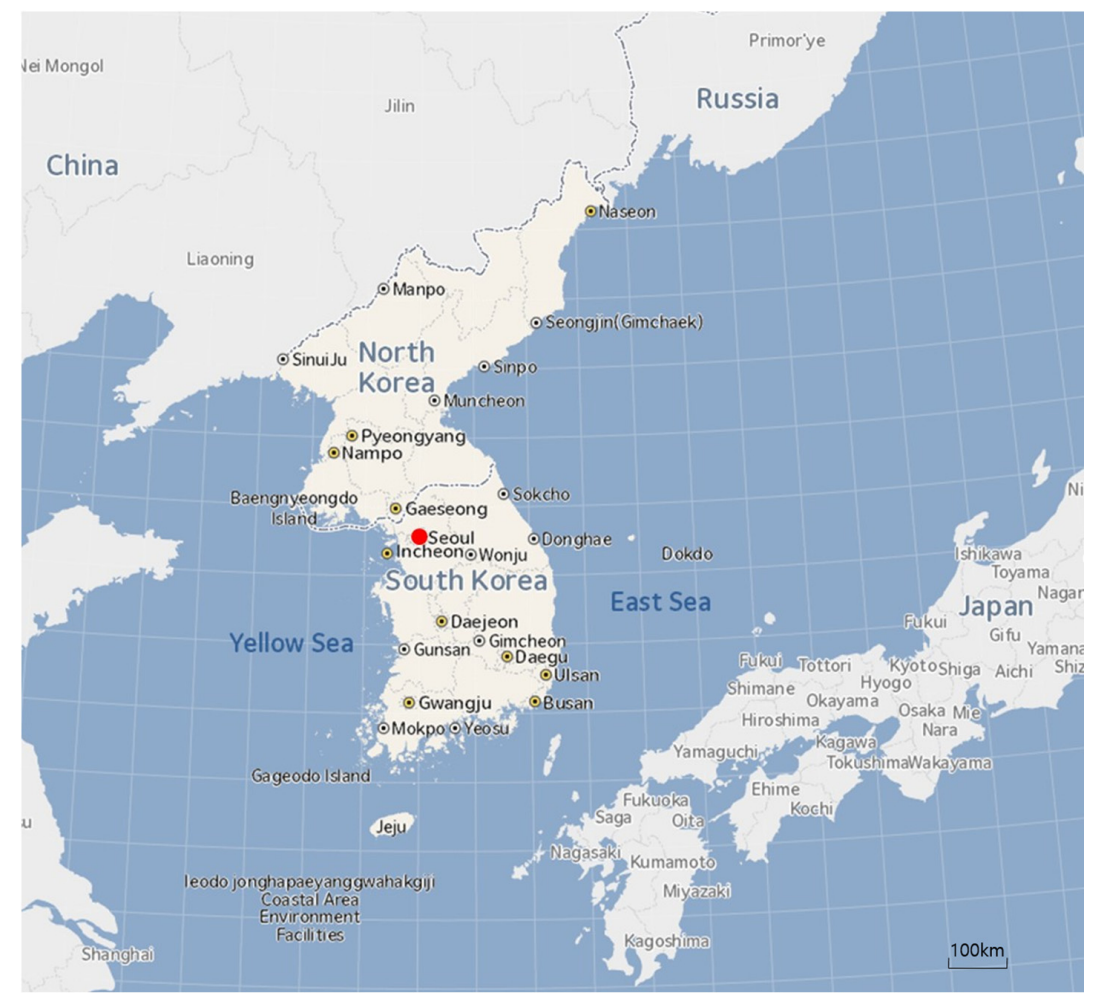

Figure 1. A map of South Korea. Source: The author took this map from National Geographic Information Platform of South Korea.

The plan for the second phase of the OLNPP was released on 20 August 2014 [36]. The SMG currently implements 88 projects in this second phase. The quantitative goals of the OLNPP have been strengthened to increasing power self-sufficiency to $20 \%$, reducing energy consumption by ten MTOE through the promotion of renewable energy and energy efficiency, and abating ten million tons of GHG emissions by 2020 (Figure 2) [35]. The OLNPP has advanced in terms of quality as well. While the first phase of the OLNPP focused on achieving quantitative targets, it currently stresses three essential values: energy independence, energy sharing, and energy involvement [35].

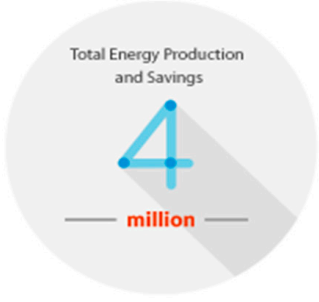

Four Million TOE

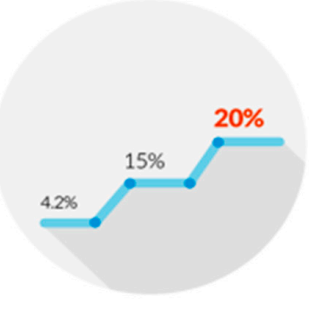

20 Percent of Energy Self-reliance Rate by 2020

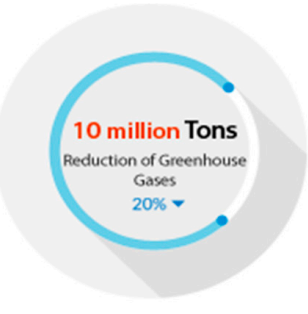

Ten Million Tons CO2/equiv

Figure 2. Targets of one less nuclear policy power plant. Source: [37]. 


\subsection{Community Building Project (CBP)}

The ESV is also a part of CBP. The CBP began in 2012 to restore communities that had been dismantled due to fast industrialization and urbanization [16]. The SMG enacted a municipal ordinance regarding Seoul Metropolitan City Community Building Supports, which came into force on 15 March 2012. CBP is defined as "activities to enhance the quality of life for residents by utilizing human and material resources, to develop inherited local traditions and features" in Article 2 of the ordinance. Article 3 stipulates the principles of CBPs as follows: "pursuit of the restoration of community, resident-driven activities based on residents' participation, respect for residents' or communities' cultural diversity and distinct characteristics, and cooperation between residents and administrative agencies." Based on this ordinance, the SMG established the Seoul Community Support Center (SCSC) as an intermediary organization to support communities in their implementation of CBPs. The SCSC supports activities that residents voluntarily and cooperatively engage in, such as community cafés, communal child-care, energy self-reliant villages, and community enterprises [38]. In general, CBPs aim to build communities by supporting the activities of groups of at least three people with shared interests or visions.

\section{Community Energy Initiatives in Seoul: The Energy Self-Reliant Village Program}

\subsection{The Status of Energy Self-Reliant Villages}

The ESV program was inspired by movements in Seongdaegol in Seoul. After the Fukushima disaster, Seongdaegol started studying energy issues and began an energy saving campaign together with GreenKorea (a Non-Governmental Organization) at the Seongdaegol Children's Library. When daycare centers closed due to the swine flu in 2009, some parents hosted an experience class for their kids, and they started discussing the establishment of a library for children so they could raise them in a safe and amiable community. The community raised KRW 20 million (about USD 17,591) and opened Seongdaegol Children's Library. About 200 residents pay monthly membership fees ranging from KRW 5000 to 20,000 for this library. The community has thus been formed, extended, and strengthened. The interests of the community expanded to include energy issues after the Fukushima disaster. Dozens of households have participated in the energy saving campaign by posting their monthly electricity consumption on the library wall. They also constructed classes and held workshops to study energy issues [16].

Based on Seongdaegol's successful experiences, the expansion of ESVs was suggested at the Policy Hearing Workshop in February 2012 and again at the Citizen's Congress in April. During the latter half of 2012, the SMG began ESV program [39]. By the end of 2016, there were 55 ESVs in Seoul (see Table 3), and 80 ESVs started their activities as of June 2017 [40]. The SMG aims to increase the number of ESVs to 100 by 2018 and to 140 by 2020.

The ESVs are categorized according to housing type into single-family home and multi-unit residential building ESVs. As of 2016, there were 34 multi-unit residential ESVs and 21 single-family home ESVs. Almost all Seoul citizens live in multi-unit residential buildings. As of 2014, 36.5\% of housing was detached in Seoul; the proportion of detached houses has decreased [41]. While size varies among individual ESVs, the average number of participants in single-family home ESVs is smaller than the number in multi-unit residential building ESVs: 158 and 267 persons, respectively [42]. In addition, unlike single-family home ESVs, priorities are similar across multi-family ESVs due to their relatively standardized building structure. 
Table 3. Energy Self-Reliant Villages in Seoul at the end of 2016.

\begin{tabular}{cccccccc}
\hline \multirow{2}{*}{ Housing Type } & \multicolumn{3}{c}{ Graduated ESVs } & \multicolumn{3}{c}{ Current ESVs Supported by the ESV Program } & \multirow{2}{*}{ Total } \\
& 5th Year & 4th Year & 3rd Year & 2nd Year & 1st Year & \\
\hline Single-family home & 4 & 2 & 1 & 6 & 8 & 21 \\
Multi-unit residential building & 2 & 2 & 3 & 11 & 16 & 34 \\
Total & 6 & 4 & 4 & 17 & 24 & 55 \\
\hline \multicolumn{7}{c}{ Source: [40]. }
\end{tabular}

\subsection{The Achievements of Energy Self-Reliant Villages}

\subsubsection{The Quantitative Achievements of Energy Self-Reliant Villages}

The ESVs accomplished both quantitative and qualitative achievements (see Table 4). The quantitative achievements include energy saving, local energy production, the spread of new energy technologies, and local economic growth. Households received 2435 energy consultations or audits from the SMG in 2016. On average, ESVs reduced electricity consumption by $12.2 \%$ in 2015 compared to 2012 levels; the highest recorded electricity consumption reduction was 35\%. In comparison, the average household electricity consumption in Seoul dropped by only $3.4 \%$ over the same period. Regarding energy efficiency improvements and new technology employment, 11,969 existing lights have been replaced by LED (Light Emitting Diode) lights and 850 building energy efficiency enhancement projects have been conducted. Also, 1396 mini solar panels with a capacity less than $1 \mathrm{~kW}$ and 34 solar panels with a capacity from 1 to $3 \mathrm{~kW}$ had been installed in $45 \mathrm{ESVs}$ as of 2016. Some ESVs installed combined heat plants and pellet boilers in residences. Some households actively adopted new energy technologies, e.g., installation of smart meters at 1181 households [43]. These ESV activities also contributed to the local economy. Sungdaegol seeks to promote its local economy through ESV activities: it operates an Energy Supermarket that sells small PV panels and energy efficient devices. These quantitative achievements varied among ESVs. For example, Sipjasung Maeul, a single-family home ESV, reduced electricity consumption by about 35\% in 2015 compared to 2012 levels. Also, a significant fraction (about $22 \%$, as of 2014) of households in that community have installed solar PV, and $45 \%$ of the community's electricity comes from solar PV [15].

Table 4. The achievements of Energy Self-Reliant Villages.

\begin{tabular}{|c|c|}
\hline Classification & Explanations \\
\hline Quantitative achievements & $\begin{array}{l}\text { - } \quad \text { Energy saving (on average } 12.2 \% \text { electricity consumption reduction in } \\
2015 \text { compared to } 2012 \text { levels) } \\
\text { - } \quad \text { Energy production (1396 mini PVs and } 34 \text { small-scale } \\
\text { PVs installments) } \\
\text { - } \quad \text { Spread new energy technologies (installation of smart meters at } \\
\text { - } 1181 \text { households) } \\
\text { Local economic promotion (e.g., Energy Supermarket) }\end{array}$ \\
\hline Qualitativeachievements & $\begin{array}{l}\text { - } \quad \text { Suggest valuable visions and values from community actions } \\
\text { - } \quad \text { Provide new models for community energy activities } \\
\text { - } \quad \text { Relieve community conflicts } \\
\text { - } \quad \text { Raise public awareness } \\
\text { - } \quad \text { Build community } \\
\text { - } \quad \text { Enhance community cohesion } \\
\text { - Carry out various experimental measures }\end{array}$ \\
\hline
\end{tabular}




\subsubsection{The Qualitative Achievements of Energy Self-Reliant Villages}

The ESVs have contributed to increased public awareness of energy and climate change issues, reduced electricity consumption, and produced energy in participating communities. Public awareness has been enhanced, as 4825 households in 45 ESVs have taken part in 523 meetings and classes organized by the SMG regarding energy and climate issues. Individual ESVs have also suggested meaningful visions and values to the SMG. For example, the energy saving activities of 3000 people in Sangol Village ESV yielded funds to install mini solar PV panels with a total capacity of $10 \mathrm{~kW}$ in 21 energy-poor households and to conduct insulation projects. By using the money saved from replacing lights at 25 apartment parking lots with LED lights, Seokgwan Dusan Apartment ESV increased the wages of apartment security guards and secured their jobs. Jeki Esoo Brownstone Apartment ESV has created a culture of energy saving by conducting lights-out campaigns every month [43]. These community activities suggest worthy visions and values. Furthermore, these bottom-up activities create innovative models for community-driven energy transition. Sungdaegol initiated Solar Loan with support from a local bank. A resident of Dongjak District, one of the 25 districts of Seoul, in which Sungdaegol is located, can install mini solar panels by paying monthly installments to a local bank with no interest or low-interest $(2 \%)$ payments. The interest paid is used to relieve energy poverty [44]. In addition, conflicts regarding inter-floor noise issues have also been solved through participating in these collective activities at Raemian Arumsup Apartment ESV [45].

\section{Municipal Support for the Energy Self-Reliant Villages}

\subsection{Municipal Support for Energy Self-Reliant Villages Regarding External Conditions}

\subsubsection{Municipal Support for Energy Self-Reliant Villages Regarding Technological Conditions}

Through the OLNPP, the SMG is trying to shift towards becoming a compact city with lower travel demands by changing the existing built environment. This shift expands pedestrian and public transportation-friendly areas. In 2014, the SMG designated Sinchon, which is surrounded by major universities and suffers from traffic congestion, as a public transport zone and improved and broadened pedestrian walkways [35]. Also, the SMG expanded the public transportation infrastructure to increase the share of public transportation travel in Seoul [35].

In the second phase of the OLNPP, the SMG annually funds research and development in seven green technology areas, such as green cars, LED lighting, and new and renewable energy. The SMG aims to create green jobs and to promote green industries through this support [35]. The SMG has also tried to develop appropriate technologies (AT) for Seoul and to apply the ATs to fields like the ESVs and energy poor households. The SMG has been developing passive building technologies to improve the residential environment of the energy poor in Seoul through a consortium that includes research institutes such as the Korea Institute of Civil Engineering and Building Technology and six private companies. It tries to apply the ATs developed to old residential buildings that house the energy poor [46]. The SMG's support changes the built environment, enhances the economic feasibility of technologies, and identifies a group of technologies that needs to be prioritized in Seoul.

\subsubsection{Municipal Support for Energy Self-Reliant Villages Regarding Non-technological Conditions}

The SMG conducts the ESV program according to a series of steps: (1) project preparation, (2) project selection, (3) implementation, and (4) evaluation (See Figure 3). Because the ESV program is also part of the CBP, the Energy Citizen Cooperation Office under the Climate and Environment Headquarters of the SMG implements this program together with the Seoul Community Support Center. The ECCO is in charge of project plan establishment and subsidy distribution, and it carries out other tasks with the support of the SCSC [39]. In the initial step of the ESV program, the SMG provides advice and guidelines regarding rules and procedures for project planning and implementation. In this first step, residents who are interested in the program gather more than three people, and 
the SMG (i.e., ECCO and SCSC) offers an education or training program regarding the CBP and the ESV program. Through this training, they learn how the ESV program works and how to build their own ESV plan. These people then build their own plans based on a survey on community status (e.g., population, energy consumption status, and energy production conditions) and discussion with community members [39].

The SMG provides expert advice to facilitate ESV activities. In the second step, plans are submitted to the Seoul Community Support Center website (www.seoulmaeul.org), and inexperienced communities can receive consultation from the Center and other experienced ESVs before proceeding [39]. In the implementation steps, communities can receive support from the ECCO, the SCSC, and district offices, and can ask the SMG to introduce professional consultants to them.

In addition, the SMG lowers barriers by financially supporting the ESVs to enable them to realize the community energy initiatives. Once a community is selected as an ESV, it can receive an annual subsidy for three years. As of 2016, ESVs have received on average about KRW 14.6 million (equivalent to about USD 12,842) through the ESV program [43]. The graduated ESVs (10 graduated ESVs in 2016, see Table 2) cannot receive the subsidy from the ESV program, but they remain eligible for educational or consulting support from it, and their activities are supported through other projects of the OLNPP. The ESV subsidies are used for community development and some ESV activities, such as consulting and campaigns [42]. Building retrofit projects and mini-solar PV installations in the ESVs are financially supported through other OLNPP projects. The ESVs are prioritized during the selection of other OLNPP projects [39].

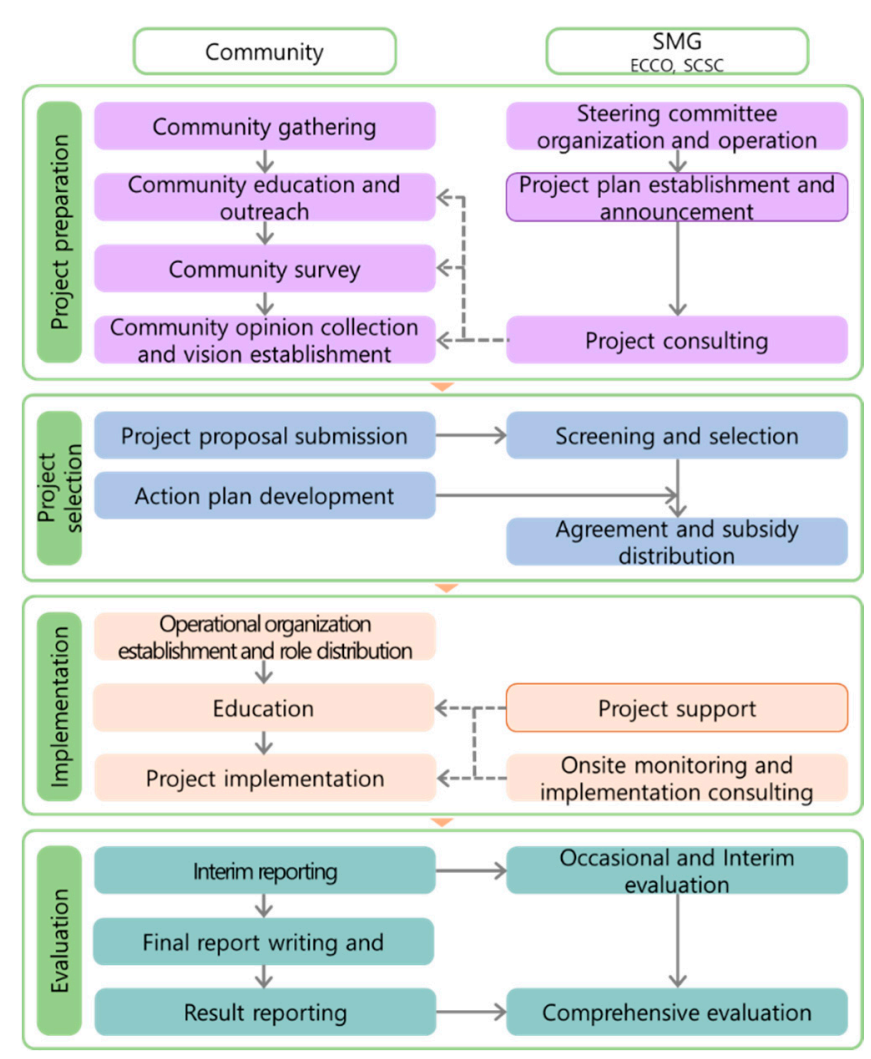

Figure 3. A flow chart for the Energy Self-Reliant Village program. Source: The author constructed this chart using Figure 5-1 in [39].

In the evaluation step, every ESV is required to present its implementation status and results at an interim evaluation meeting and a final evaluation meeting. The center reviews the final report and identifies individual ESV issues, which helps enhance the next year's plan [39]. 
The ESV program has been in place since 2012 as a part of the OLNPP and the CBP. For the past five years, relevant ordinances and policy measures have been established. In addition to the ordinance regarding the $\mathrm{CBP}$, an ordinance regarding cooperatives promotion and an ordinance regarding social economy have been enacted. In 2013, the first energy cooperative, the Seoul Citizen Solar Power Cooperative, was established. As of October 2014, there were 12 solar power cooperatives in Seoul [47]. In addition, in 2013 the SMG introduced feed-in-tariffs (FIT) that pay KRW 50 (USD 4 cents) per kWh of electricity generated by a small-scale PV (one with a capacity from $3 \mathrm{~kW}$ to $50 \mathrm{~kW}$ ). Thanks to these laws and subsidies, the cooperatives could install small-scale PVs. The SMG cheaply rents its unused spaces to developers who installed PV plants of up to $22.8 \mathrm{MW}$ [35]. Also, to promote and facilitate collective action, the SMG provides various classes and workshops to cultivate community activists. Through these classes and workshops, the SMG trained 95 people as energy designers and 250 people as energy consultants in 2014 [39]. With clear direction and financial support, the OLNPP and the CBP changed market attitudes about renewable energy and created business opportunities and new players.

\subsection{Municipal Support for Energy Self-Reliant Villages Regarding Internal Context}

In addition to affecting external conditions, the SMG has contributed to changing conditions internal to communities. As mentioned earlier, the ESV program was initiated following the model of the grassroot movement in Sungdaegol, where pioneering activists and entrepreneurial individuals engaged in community actions concerning the safety of nuclear energy [16]. The SMG institutionalized the collective actions of these entrepreneurial individuals into the ESV program. The SMG reflects the ideas of pioneering activists not only in the ESV program but also in the OLNPP. The OLNPP is being designed and implemented through governance in which various stakeholders participate [48]. The SMG operates regular advisory groups, which consist of stakeholders from academia, NGOs, and other related organizations. The Implementation Council for One Less Nuclear Power Plant (IC-OLNPP) is one of the regular advisory groups [48]. This council comprises several divisions, including the Energy Community/Welfare Division. The members of this division meet monthly with SMG officials and discuss relevant OLNPP projects. A pioneering ESV leader attends the meetings of the division and offers opinions based on on-site experiences, and the SMG tries to improve the ESV program according to the submitted ideas and opinions.

Even before the commencement of the ESV program, there were several communities with strong community spirit or local traditions and history with cooperatives. The installation of solar PVs in Sipjasung Village can be attributed to the stronger cohesion of that community. Sipjasung includes 46 households of Vietnam War veterans, who jointly purchased land and built the village using subsidies granted by the president and donated funds [39]. The shared emotional connection that has been built based on that common experience contributes to its community spirit [45]. Sungdaegol also has a history of cooperation for communal childcare [16]. However, not all the ESVs have these experiences. Based on the vision for energy self-sufficiency that the SMG has established for the ESV program, any group of people can gather and learn the value of community and community action, and learn how to participate in the ESV program. As they take various classes and workshops from the SMG, public awareness can be enhanced, and community spirit can be raised. Also, their sense of locality and responsibility can increase.

Communities establish and maintain a community organization with support from the SMG on conducting effective team leadership. In the project preparation stage, people learn and understand the value of communities [39]. In the implementation step, communities organize key participants for planned projects or tasks. The SMG provides guidelines on how to designate key members. For example, key members can be designated based on the features of the planned projects, such as community festivals, communal childcare, and community enterprises, or based on roles such as administrative support, education, and outreach. In addition, the various classes and workshops that the SMG provides foster activists who can play a significant role in community organization [39]. 
In addition, the ESV program is shaped, implemented, and developed through its governance, which various stakeholders participate in. In addition to the IC-OLNPP, the SMG holds conferences and workshops where residents of ESVs can communicate with officials of the SMG and attendees from the private sector. For example, on 25 April 2017, the SMG held the first online and offline forum regarding the spread of new industry in the ESVs. During these communication opportunities, individual ESVs can network with other ESVs and stakeholders.

\subsection{The Role of the Municipal Government in Creating Enabling Conditions}

The role of local government in promoting community engagement in energy transition has been emphasized and recognized by the central government in the UK $[49,50]$. Unlike in the UK, Denmark, and Germany [19,51], the role of local governments is very limited in South Korea. Energy systems and relevant policies are centralized in South Korea, and national energy policies are unsupportive for energy transition [52]. While the role of community energy initiatives has been emphasized in European countries, it has not been recognized by the national government in South Korea. In this unsupportive context, Seoul breaks ground by enabling community engagement in energy transition in South Korea. The SMG's ESV program promotes community energy initiatives. ESVs produced qualitative and quantitative achievements and created unique models for community energy initiatives. Table 5 summarizes how the SMG creates internal and external conditions that enable ESVs to achieve success.

In terms of conditions external to the community, the SMG successfully conducted 'the enabling mode of governing' by raising public awareness, granting financial support, coordinating partnerships with various stakeholders, and providing guidelines [34]. In addition to subsidies for the ESVs, the OLNPP project provides various financial support such as subsidies for mini solar PV installments, FIT for small-scale PV installments, and low-interest loans for building retrofits. Unlike the UK, where the national government supports the community energy projects in urban areas by setting up the Urban Community Energy Fund [53], the SMG established the budget for the ESV program and supports the ESVs itself. In addition, the ESV program is effective in that the ESVs have continuously grown in number. This program has spread to other regions in South Korea, while the growth of community energy initiatives has decreased in the UK due to a cut in the FIT program [54]. The SMG also supports the ESVs by carrying out the mode of 'governing by authority' based on regulations and directions [34]. The SMG reformed the relevant ordinances and policies to enable a shift to being a less-consuming city.

Acting together has various benefits. Still, community energy initiatives face various challenges, such as lack of expertise and financial difficulties. [32,55]. Therefore, collective actions need support from national and local governments. Local government can play a significant role in promoting collective actions because they are closer to the people and thus can understand the local situation and priorities better [56]. Beyond the changes in Seoul, the SMG also affected wider external conditions. The SMG's efforts influenced national energy policies and other local government programs through the proven effectiveness of its effort. making suggestions based on the proven effectiveness of its effort. For example, the subsidy for mini-solar PV installments has been institutionalized as a national program starting in 2017. In addition, the SMG requested the enhancement of relevant national policies and laws that conflict with parts of the OLNPP. Higher policies have, thereby, been enhanced.

Since spontaneous community development is difficult in urban areas, communities need to be cultivated there [11]. Communities have been dismantled due to fast industrialization and urbanization in South Korea [16]. Practical capacities (e.g., time) are also one of the important factors for the success of community actions [57]. Time for people to allocate to collective action is relatively limited in South Korea, where in 2015 people worked the third-longest hours among the OECD countries [58]. Therefore, community spirit and a sense of locality and responsibility are unlikely to spontaneously develop without support in Seoul. The ESV program provides clear direction and vision for people to follow. Through acting together with the SMG's financial and informative support for the vision it has suggested, a sense of locality and responsibility and community spirit is raised, and communities can 
specify their own visiontailored to individual community status. In this way, the SMG has contributed to shaping the enabling internal conditions for the community.

Table 5. Summary of Seoul's supports for Energy Self-Reliant Villages (ESVs).

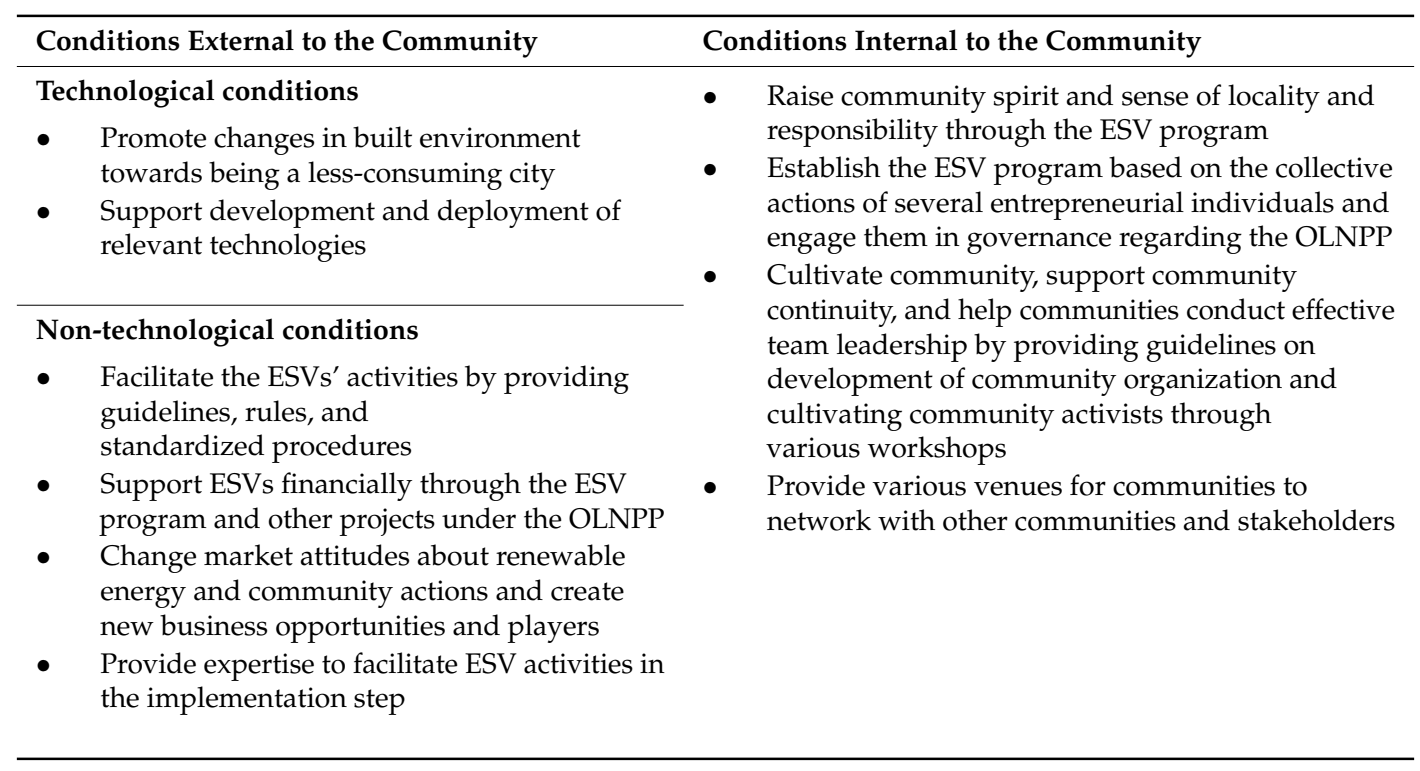

\section{Unsolved Internal and External Challenges to Energy Self-Reliant Villages}

Community energy initiatives face technological, legal, financial, political, physical, and organizational challenges [32,55]. The SMG supports ESVs by improving both the internal and external context of the community, consequently lowering the barriers that communities could have faced and enabling the ESVs to accomplish notable achievements. However, there are still unsolved challenges.

\subsection{External Challenges to the Energy Self-Reliant Villages}

With densely placed buildings, there are not many energy production options in Seoul. Solar PV is one of the viable options for producing energy through community activities in the city [59]. However, installation of PV solar is not easy in Seoul. Because many of Seoul's citizens live in multi-unit residential buildings, the rooftops available for PV installation are not enough, and options for citizens to participate in energy production are limited. Although the OLNPP incorporates changes in the built environment that can result in a less energy-consuming city, particularly in the transportation sector [35], it does not incorporate a long-term plan to improve the built environment of the city so it can produce more energy. Since the layout of buildings and infrastructure affects energy consumption patterns for a long time, changes in the built environment also need to be considered from the perspective of energy production $[60,61]$.

Initially, the ESVs conducted projects in this order: (1) energy saving, (2) energy efficiency enhancement, and (3) energy production. When they reached the limits of further energy saving measures, they turned to energy efficiency measures to obtain additional savings. When they reached the limit of these energy efficiency measures, they could then implement energy production measures. ESVs now conduct all three types of projects simultaneously in the initial year because there are best practices that they can follow. As a result, they can achieve great improvements in that first year. However, this means they are doomed to face stagnant energy savings or energy production in subsequent years. Because ESV evaluators require continuous enhancements in community actions, community leaders express concerns about the evaluation criteria (Interview 2017.3.22). When the projects are difficult or complicated, people are discouraged from joining the collective actions [25]. The evaluation criteria need to be changed. 
Seoul has an aggressive target of increasing the number of ESVs to 100 by 2018. The Energy Citizen Cooperation Office consists of 13 staffs. A single person is in charge of all 80 current ESVs. Also, although the SMG is trying to promote the participation and cooperation of district offices in the operation of this program, it is still mostly handled by the SMG itself. Therefore, the SMG faces limitations of administrative capacity, which might reduce its ability to enhance non-technological conditions by providing advice and guidelines about the rules and offering expertise in project planning and implementation. As these bottom-up actions involve direct participation by various stakeholders and many participants [62], more points of connection (e.g., intermediary organizations) are necessary to facilitate the programs.

Although significant parts of these policies were developed by the previous mayor, Sehun Oh [63], the success of the ESV program can be attributed to Mayor Wonsoon Park's emphasis on citizen engagement $[48,64]$. The continuity of ESVs is heavily dependent on the current enabling municipal policy arrangements. In other words, the commitment and interest of elected leaders plays a significant role in promoting community engagement in energy transition. In turn, success is closely related to funding [51]. Therefore, if the mayor was not re-elected and the amount of public engagement in the OLNPP decreased, the continuity of the ESVs would be called into question.

Another challenge is that energy systems and markets are shaped by the central government in South Korea [52]. Although the SMG actively implements the ESV program using various measures, decisions made by the central government on energy systems or institutions sometimes discourage the ESVs' activities. For example, the main reason for households in ESVs to install mini-solar PVs is to save electric charges by dropping to a lower consumption range in residential progressive electricity tariffs. However, the central government last year lowered progressive electricity tariffs from July to September, which reduced the incentive for mini PV installation (Interview, 2015.11.26). Also, the enabling environment for continuous community activities needs to be built without relying on support from the municipal government. Through participating in the ESV program, the residents, especially leaders, have enhanced their capacity; however, the energy system and economy have not been prepared to accept their activities (Interview 2017.4.12) [39]. For example, solar PV technology has not achieved grid parity in South Korea $(0.08 / 0.16)$, in contrast to Australia $(0.49 / 0.15)$, France $(0.21 / 0.16)$, Germany $(0.33 / 0.19)$, Japan $(0.28 / 0.14)$, New Zealand $(0.2 / 0.18)$, Spain $(0.24 / 0.14)$, and the United States $(0.39 / 0.17)$ (The numbers within parentheses are average electricity price, and the price of electricity generated from solar PVs, where the unit of measurement is $\$ / \mathrm{kWh}$ ) [65]. Economic gains are a major driver in some energy communities [25]. However, the contextual and structural conditions for community energy initiatives do not provide considerable financial incentives for community action or citizen engagement in Korea. Therefore, higher-level policies and systems are barriers to community energy transition activities, as was also found by Mey et al. [51].

\subsection{Internal Challenges to the Energy Self-Reliant Villages}

Some ESVs struggle due to internal issues. These internal challenges are mainly related to the continuity of the community organization, which depends on community leaders. Although the ESV program provides guidelines on how to organize an effective operational team, ESV performance is heavily dependent on a few leaders. Leaders have played pivotal roles in the ESV projects ever since such leaders initiated the ESV plan and acted as a bridge to communicate with SMG officials [39]. However, leaders frequently receive criticism from some residents. For example, when leaders select a contractor for replacing existing lighting systems, groundless criticisms-for instance, that they personally benefit from the contractor decision process-discourages ESV leaders from continuing in that role (Interview 2015.11.26.).

In addition, the change or absence of leaders has often resulted in the suspension of an ESV program. For example, a very proactive ESV suspended its community actions in 2017 due to a change of leaders (Interview 2017.3.22). A community that has experience with conducting small projects or had ties between neighborhoods before the commencement of the ESV activities has a more cohesive 
sense of community. These areas with a relatively longer sense of community are more likely to survive by finding new leaders. However, in newly organized communities that apply to the ESV program, deeper ties have not developed yet. As a result, these groups might easily lose momentum or motivation for participation in the ESV program if the leader is changed or moves out.

\section{Conclusions}

The ESV is a great model for fostering collective actions for energy transition, especially for a metropolitan city, where the ties between neighborhoods continuously weaken, or communities are rarely created. Lifestyle is entirely different in urban areas, and particularly in South Korea. It is not favorable to the development of communities. People have difficulty investing their time in community energy actions because they come home very late and often work on weekends. Also, community energy initiatives are unlikely to spontaneously spread under the current structural conditions: economic gains from these activities are difficult to realize. In these circumstances, the ESV program promotes community actions for energy transition in Seoul by creating enabling conditions. This enabling municipal program has encouraged community energy initiatives despite hindering national energy policies. Beyond creating enabling conditions within Seoul, the SMG contributes to changing national policies and other regional policies by proving the performance of the enabling approaches and recommending the enhancement of relevant policies and laws at the national level.

Thanks to the SMG's support, ESVs have accomplished quantitative and qualitative achievements. In addition, individual ESV activities have established a new model for community initiatives for energy transition. Along with the community energy activities, including education for enhancing public awareness, energy saving campaigns, and renewable energy cooperatives, the ESVs conducted unique activities to relieve energy poverty using economic gains from the collective actions for energy transition.

Although the ESVs produced impressive achievements, the ESVs have several unsolved challenges. Some of these issues can be attributed to higher-level structural factors such as national energy policy or energy systems. In South Korea, since the market and the system are not favorable for the private sector and citizens, citizens' engagement in energy transition does not easily spread. This implies that, in addition to municipal level support, national policies and systems need to be reframed to stimulate community-driven energy transition.

Other challenges are internal to communities. The sustainability of community energy initiatives comes into question due to their heavy dependence on a few community leaders. Also, groundless criticisms and conflicts among members might impede energy transition. Therefore, it should be noted that community energy initiatives are not a panacea for energy transition in urban areas. ESV project procedures need to be more transparent. For example, if communities could use products purchased by the municipal government, the burden on the community leader to find appropriate products would be relieved, and criticisms of the leader could be reduced.

Lastly, because of its emphasis on the role of the municipal government, this study has analyzed other stakeholders, such as investors and utilities, only as actors reacting to the SMG's ordinances and supports. Further research needs to explore how these other stakeholders influenced the rise of community energy in Seoul.

Acknowledgments: This work has been financially supported by Korea Ministry of Environment (MOE) as Graduate School Specialized in Climate Change. The author expresses a sincere gratitude to the reviewers whose comments enriched this paper.

Conflicts of Interest: The author declares no conflict of interest. 


\section{References}

1. Petersen, J.-P. Energy concepts for self-supplying communities based on local and renewable energy sources: A case study from northern Germany. Sustain. Cities Soc. 2016, 26, 1-8. [CrossRef]

2. Feldhoff, T. Asset-based community development in the energy sector: Energy and regional policy lessons from community power in Japan. Int. Plan. Stud. 2016, 21, 261-277. [CrossRef]

3. Magnani, N.; Osti, G. Does civil society matter? Challenges and strategies of grassroots initiatives in Italy's energy transition. Energy Res. Soc. Sci. 2016, 13, 148-157. [CrossRef]

4. Burchell, K.; Rettie, R.; Roberts, T.C. Householder engagement with energy consumption feedback: The role of community action and communications. Energy Policy 2016, 88, 178-186. [CrossRef]

5. Rogers, J.C.; Simmons, E.A.; Convery, I.; Weatherall, A. Social impacts of community renewable energy projects: Findings from a woodfuel case study. Energy Policy 2012, 42, 239-247. [CrossRef]

6. Hargreaves, T.; Hielscher, S.; Seyfang, G.; Smith, A. Grassroots innovations in community energy: The role of intermediaries in niche development. Glob. Environ. Chang. 2013, 23, 868-880. [CrossRef]

7. Bauwens, T. Explaining the diversity of motivations behind community renewable energy. Energy Policy 2016, 93, 278-290. [CrossRef]

8. REScoop. Facts \& Figures. Available online: https:/ / rescoop.eu/facts-figures-0 (accessed on 8 July 2017).

9. REN21. Renewable 2016 Global Status Report; Renewable Energy Policy Network for the 21st Century: Paris, France, 2016.

10. Klein, S.J.W.; Coffey, S. Building a sustainable energy future, one community at a time. Renew. Sustain. Energy Rev. 2016, 60, 867-880. [CrossRef]

11. Ranade, S.N. Urban community development-Its nature and scope. Econ. Wkly 1959, 11, 1501-1502.

12. Secretary General of the United Nations. The applicability of community development to urban areas. Ek 1961, 12, 284-288.

13. McMillan, D.W.; Chavis, D.M. Sense of community: A definition and theory. J. Community Psychol. 1986, 14, 6-23. [CrossRef]

14. Yun, S.-J. Contact between Taiwan's anti-nuclear movement and Seoul's one less nuclear power plant. AJES 2015, 55, 98-105. (In Korean)

15. Climate \& Environment Headquarters. The Third Implementation Council for One Less Nuclear Power Plant-The Second Meeting Materials for Energy Community Welfare Division; Seoul Metropolitan Government (SMG): Seoul, Korea, 2017. (In Korean)

16. Kim, D.; Kim, M.; Kim, S.; KimYi, J.; Kim, Y.; Baek, H.; Seo, J.; Yu, C.; Jo, S. Seoul Embraces Villages; Seoul Metropolitan Government (SMG): Seoul, Korea, 2012. (In Korean)

17. Park, J.; Yun, S.-J. The formation process of energy citizenship in urban community energy transition movements seen through the case of Sungdaegol village in Seoul. Space Environ. 2016, 26, 79-138. (In Korean)

18. Cho, M.S.; Yun, S.-J. Learning of ecological citizenship through the process of energy transition movements: Based on a qualitative case study on an energy self-sufficient village in Gwanak-gu, Seoul South Korea. Space Environ. 2016, 26, 190-228. (In Korean)

19. Sperling, K. How does a pioneer community energy project succeed in practice? The case of the samsø renewable energy island. Renew. Sustain. Energy Rev. 2017, 71, 884-897. [CrossRef]

20. Lee, Y. Rural energy self-reliant villages for the oil era. Hum. Settlements 2010, 350, 28-35. (In Korean)

21. Gusfield, J.R. Community: A Critical Response; Harper \& Row: New York, NY, USA, 1978.

22. Jeong, Y.; Simcock, N.; Walker, G. Making power differently: Exploring the motives and meanings of community renewable energy development in cases from the UK and South Korea. In Enterprising Communities: Grassroots Sustainability Innovations; Davies, A., Ed.; Emerald Group Publishing Limited: Bradford, UK, 2012.

23. Walker, G. What are the barriers and incentives for community-owned means of energy production and use? Energy Policy 2008, 36, 4401-4405. [CrossRef]

24. Cho, M.-J.; Lee, Y.-K.; Lim, U. A site selection of a special school for the disabled students: Focused on Jungnang-gu in Korea. JKPA 2015, 50, 87-106. (In Korean) [CrossRef]

25. Dóci, G.; Vasileiadou, E. "Let's do it ourselves" individual motivations for investing in renewables at community level. Renew. Sustain. Energy Rev. 2015, 49, 41-50. [CrossRef] 
26. Gubbins, N. The Role of Community Energy Schemes in Supporting Community Resil; Joseph Rowntree Foundation: York, UK, 2010.

27. Walker, G.; Devine-Wright, P. Community renewable energy: What should it mean? Energy Policy 2008, 36, 497-500. [CrossRef]

28. Kalkbrenner, B.J.; Roosen, J. Citizens' willingness to participate in local renewable energy projects: The role of community and trust in Germany. Energy Res. Soc. Sci. 2016, 13, 60-70. [CrossRef]

29. Bauwens, T.; Gotchev, B.; Holstenkamp, L. What drives the development of community energy in Europe? The case of wind power cooperatives. Energy Res. Soc. Sci. 2016, 13, 136-147. [CrossRef]

30. Oteman, M.; Wiering, M.; Helderman, J.-K. The institutional space of community initiatives for renewable energy: A comparative case study of the Netherlands, Germany, and Denmark. Energy, Sustain. Soc. 2014, 4, 11. [CrossRef]

31. Schut, M.; van Paassen, A.; Leeuwis, C.; Bos, S.; Leonardo, W.; Lerner, A. Space for innovation for sustainable community-based biofuel production and use: Lessons learned for policy from Nhambita community, Mozambique. Energy Policy 2011, 39, 5116-5128. [CrossRef]

32. Schoor, T.v.d.; Scholtens, B. Power to the people: Local community initiatives and the transition to sustainable energy. Renew. Sustain. Energy Rev. 2015, 43, 666-675. [CrossRef]

33. Hicks, J.; Mey, F. Government Support Options for Community Energy: Best Practice International Policy; Community Power Agency: Sydney, Australia, 2014.

34. Bulkeley, H.; Kern, K. Local government and the governing of climate change in Germany and the UK. Urban Stud. 2006, 43, 2237-2259. [CrossRef]

35. SMG. One Less Nuclear Power Plant, Phase 2; Seoul Metropolitan Government: Seoul, Korea, 2014.

36. SMG. One Less Nuclear Power Plant; Seoul Metropolitan Government: Seoul, Korea, 2013.

37. SMG. One Less Nuclear Power Plant 2-Seoul Sustainable Energy Action Plan. Available online: http:/ / english.seoul.go.kr/policy-information/environment-energy/climate-environment/5-oneless-nuclear-power-plant-2/ (accessed on 20 May 2017).

38. SCSC. Support Projects in Seoul. Available online: http://www.seoulmaeul.org/Programs/User/support/ seoul_support/index.asp (accessed on 13 April 2017). (In Korean)

39. Kim, M.; Yang, J.; Kim, J. Seoul Energy Self-sufficient Village Development and Operation Manual; Seoul Metropolitan Government (SMG): Seoul, Korea, 2015. (In Korean)

40. Climate \& Environment Headquarters. The Third Implementation Council for One Less Nuclear Power Plant-The First Meeting Materials for Energy Community Welfare Division; Seoul Metropolitan Government (SMG): Seoul, Korea, 2017. (In Korean)

41. SMG. Housing Status in Seoul (Housing Type, Occupancy Type, etc.); Seoul Metropolitan Government (SMG): Seoul, Korea, 2015. (In Korean)

42. SMG. 2016 Final Achievement Report of Energy Self-Reliant Villages; SMG: Seoul, Korea, 2017. (In Korean)

43. Energy Citizen Cooperation Office. Energy Citizen Cooperation Office. Creation of Energy Self-Reliant Villages (Matter of Interest of Councilman); SMG: Seoul, South Korea, 2017. (In Korean)

44. Choi, Y. The answer of Sungdaegol to the possibility of energy self-sufficiency. Newsnjoy February.2.2017, 2017. (In Korean)

45. SMG. Manual for Energy Self-Reliant Village; Seoul Metropolitan Government (SMG): Seoul, Korea, 2015. (In Korean)

46. Climate \& Environment Headquarters. The Seoul Metropolitan Government Promotes Energy Efficiency Enhancement Projects for Low-Income Households; Climate \& Environment Headquarters: Seoul, Korea, 2017. (In Korean)

47. Park, J.H. The state and tasks of energy cooperatives in Korea: From the perspective of energy citizenship. ECO 2015, 19, 173-211. (In Korean)

48. Lee, T.; Lee, T.; Lee, Y. An experiment for urban energy autonomy in Seoul: The one 'less' nuclear power plant policy. Energy Policy 2014, 74, 311-318. [CrossRef]

49. Fudge, S.; Peters, M. Motivating carbon reduction in the UK: The role of local government as an agent of social change. J. Integr. Environ. Sci. 2009, 6, 103-120. [CrossRef]

50. Peters, M.; Fudge, S.; Sinclair, P. Mobilizing community action towards a low-carbon future: Opportunities and challenges for local government in the UK. Energy Policy 2010, 38, 7596-7603. [CrossRef] 
51. Mey, F.; Diesendorf, M.; MacGill, I. Can local government play a greater role for community renewable energy? A case study from Australia. Energy Res. Soc. Sci. 2016, 21, 33-43. [CrossRef]

52. Lee, Y. Energy Management Policy (1997-2014). Available online: https://seoulsolution.kr/en/node/3495 (accessed on 23 May 2017).

53. DECC. Community Energy Strategy: Full Report; Department of Energy \& Climate Change: London, UK, 2014.

54. Harvey, F. Just 10 new community energy schemes registered after Tories cut subsidies. The Guardian, 12 September 2016.

55. Van Der Schoor, T.; Van Lente, H.; Scholtens, B.; Peine, A. Challenging obduracy: How local communities transform the energy system. Energy Res. Soc. Sci. 2016, 13, 94-105. [CrossRef]

56. Van Staden, M. Sustainable energy transition: Local governments as key actors. In Towards 100\% Renewable Energy: Techniques, Costs and Regional Case-Studies; Uyar, T.S., Ed.; Springer International Publishing: Cham, Switzerland, 2017; pp. 17-25.

57. Park, J.J. Fostering community energy and equal opportunities between communities. Local Environ. 2012, 17, 387-408. [CrossRef]

58. OECD. Hours Worked (Indicator). Available online: https://data.oecd.org/emp/hours-worked.htm (accessed on 8 July 2017).

59. Gautam, B.R.; Li, F.; Ru, G. Assessment of urban rooftop solar photovoltaic potential to solve power shortage problem in Nepal. Energy Build. 2015, 86, 735-744. [CrossRef]

60. IRENA. Renewable Energy in Cities; International Renewable Energy Agency (IRENA): Abu Dhabi, UAE, 2016.

61. Cotgrave, A.; Riley, M. Total Sustainability in the Built Environment; Palgrave: London, UK, 2012.

62. Khadka, C.; Vacik, H. Comparing a top-down and bottom-up approach in the identification of criteria and indicators for sustainable community forest management in Nepal. Forestry 2012, 85, 145-158. [CrossRef]

63. Lee, K. Energy politics and civil governance of mayor Park Wonsoon in metropolitan Seoul. Econ. Soc. 2015, 107, 140-172. (In Korean)

64. Kim, H. An analysis of Seoul's energy transition from an integrated multilevel governance perspective. Space Environ. 2016, 26, 334-364.

65. Lee, Y. Overview and domestic and foreign status of e-prosumer. KEMRI Electr. Econ. Rev. 2016, 7, 7-10. (In Korean) 